\title{
KVALITETA ŽIVOTA ŽENA OBOLJELIH OD RAKA DOJKE NA PODRUČJU LIVNA
}

\author{
Roberta Perković, Andrea Vlašić, Antonija Hrkać, Ivan Vasilj \\ Fakultet zdravstvenih studija, Sveučilište u Mostaru, Bijeli Brijeg bb \\ Mostar 88000, Bosna i Hercegovina \\ Rad je primljen 18.1.2018. Rad je recenziran 21.2.2018. Rad je prihvaćen 13.3.2018.
}

\section{SAŽETAK}

UVOD: Rak dojke je najčešća zloćudna bolest kod žena, a s povećanjem životne dobi rizik raka raste. Samoprocjena kvalitete života kod osoba s malignitetom danas je cilj mnogih istraživanja, ponajprije radi poboljšanja rehabilitacijskih i terapijskih postupaka, te što dugotrajnijeg i kvalitetnijeg preživljavanja. Cilj istraživanja je ispitati kvalitetu života žena oboljelih od raka dojke na području Livna.

ISPITANICI I METODE: Presječna studija je provedena na uzorku od 65 ispitanica ( $\mathrm{n}=65)$. Kriteriji uključenja bili su: žene oboljele i liječene od raka dojke na području Livna, te zdrave žene (tj. bez raka). Kriteriji isključenja: žene koje nisu članice Udruge žena oboljelih od raka dojke "Bistrica" (klinički uzorak), dob manja od 18 godina, ispitanice s psihijatrijskom dijagnozom, te one s više kroničnih bolesti radi mogućeg utjecaja na kvalitetu života. Podaci su prikupljeni na osnovu upitnika: upitnik sa sociodemografskim obilježjima i upitnik kvalitete života (WHOQOL-BREF).

REZULTATI: U kliničkom uzorku je više visoko obrazovanih žena i onih koje žive same. Ispitanice iz kliničkog uzorka najvišom su procijenile kvalitetu svog psihološkog stanja, a najnižom kvalitetu socijalnih interakcija. Dokazano je statistički značajno manje zadovoljstvo fizičkim zdravljem kod ispitanica kliničkog uzorka.

ZAKLJUČAK: Nije nađena statistički značajna razlika u općem zadovoljstvu kvalitetom života kod žena oboljelih od raka dojke u odnosu na zdrave žene. Najveća razlika između oboljelih i zdravih žena je u zadovoljstvu prijevoznim sredstvima, sposobnosti obavljanja svakodnevnih poslova i prihvaćanju izmijenjenog tjelesnog izgleda.

Ključne riječi: kvaliteta života, rak dojke, žena

Osoba za razmjenu informacija:

Roberta Perković

Županijska bolnica „Dr. fra Mihovil Sučić“ Livno

rperkovic73@gmail.com

\section{UVOD}

Rak dojke je najčešća zloćudna bolest kod žena, a s povećanjem životne dobi rizik raka raste (1). Rizik pojave raka dojke povećan je kod žena s ranom prvom mjesečnicom, te kasnom menopauzom, nerotkinja ili žena koje su rodile poslije 35 godina života, žena s prekomjernom tjelesnom težinom, kod primjene estrogena u menopauzi, konzumiranja hrane bogate životinjskim mastima i alkohola. Nije potvrđen rizik za obolijevanje kod uporabe oralne kontracepcije (2). Uvećan rizik postoji i kod žena čije su majke ili sestre oboljele od raka dojke prije menopauze (3). Izlaganje ionizirajućem zračenju pridonosi razvoju raka dojke, posebice kod mlađih žena (4). Etiopatogeneza raka dojke je bez sumnje kompleksna i vjerojatno više čimbenika zajedno dovodi do ranih patoloških promjena u epitelu dojke koje na kraju rezultiraju karcinogenezom (5). Godišnje u Hrvatskoj oboli oko 2.500 žena (6). Rak dojke kod žena u BiH je niži u odnosu na Europu, te je stopa mortaliteta manja od 15/100 000 stanovnika, a stopa incidencije manja od 40/100 000 stanovnika (7). 
Mamografija može otkriti rak dojke do dvije godine ranije nego što tumor postane dovoljno velik da se može napipati. Ako se rak dojke otkrije dovoljno rano, petogodišnje preživljenje je 97 \% (8).

\section{Kvaliteta života}

Kvaliteta života iznimno je složen koncept kojim se bave različite znanstvene discipline. Autori Felce i Perry definiraju kvalitetu života kao sveukupno, opće blagostanje koje uključuje objektivne čimbenike i subjektivno vrednovanje fizičkog, materijalnog, socijalnog i emotivnog blagostanja, zajedno s osobnim razvojem i svrhovitom aktivnošću, a sve vrednovano kroz osobni skup vrijednosti određene osobe. Po pitanju povezanosti objektivnih i subjektivnih pokazatelja, opažena je slaba povezanost između čovjekovog subjektivnog osjećaja zadovoljstva životom kao i vlastite procjene kvalitete života i objektivnih životnih uvjeta (9). Cella i Tulsky navode četiri osnovne dimenzije kvalitete života: tjelesna, poslovna, emocionalna i socijalna dobrobit (10). Danas postoje različite metode procjene kvalitete života. Procjenjuje li se kvaliteta života s medicinskog stajališta, fokus je na bolesti i poteškoćama koje iz nje proizlaze. Procjena sa stajališta zdravlja usmjerena je ka sposobnostima pojedinca i vrednovanju zdravlja.

\section{Kvaliteta života i rak dojke}

Unatoč velikim iskoracima u liječenju malignih bolesti, tijek bolesti, liječenje i psihološki izazovi negativno utječu na kvalitetu života (11). Emocionalna trauma dovodi do povećanog osjećaja ranjivosti, gubitka kontrole i neizvjesnosti. Kirurško, kemoterapijsko, radioterapijsko i hormonsko liječenje uzrokuje veliki broj tjelesnih i endokrinoloških simptoma (12). Žene čije je mentalno zdravlje bilo narušeno prije dijagnoze, loše reagiraju na dijagnozu i njihovo mentalno zdravlje se još više pogoršava (13). Husić i Žargović u istraživanju provedenom 2010. godine najlošijim procjenjuju mentalno zdravlje kod oboljelih žena (14). Studija na uzorku iz Malezije pokazuje da su važni prediktori kvalitete života kod oboljelih žena obrazovni status i starosna dob. Kvaliteta je procijenjena višom kod starijih ispitanica, te onih s visokom naobrazbom. Najveće smetnje koje utječu na kvalitetu života su izmijenjeni tjelesni izgled (gubitak kose), kognitivne i financijske poteškoće (15). Kliničko istraživanje provedeno u $\mathrm{BiH}$ pokazuje statistički značajno nižu kvalitetu života oboljelih od raka dojke u odnosu na zdrave žene, te da bolest znatno mijenja psihološko i socijalno funkcioniranje ispitanica (16).

Samoprocjena kvalitete života kod osoba s malignitetom danas je cilj mnogih istraživanja, ponajprije radi poboljšanja rehabilitacijskih i terapijskih postupaka, te što dugotrajnijeg i kvalitetnijeg preživljavanja.

\section{CILJ ISTRAŽIVANJA}

Cilj istraživanja bio je ispitati kvalitetu života žena oboljelih od raka dojke na području Livna.

\section{ISPITANICI I METODE Ispitanici}

Presječna studija provedena je na području Livna u veljači 2017. godine na uzorku od 65 ispitanica $(\mathrm{n}=65)$. Uzorak su sačinjavale klinička i neklinička skupina. Kliničku skupinu činile su žene oboljele i liječene od raka dojke $(n=32)$, članice Udruge žena oboljelih od raka dojke "Bistrica" Livno. Nekliničku skupinu činile su ispitanice kod kojih nije dijagnosticiran rak dojke $(\mathrm{n}=33)$, odabrane metodom namjernog uzorkovanja. Pri tome se vodilo računa da po starosnoj dobi, mjestu stanovanja i socioekonomskom statusu budu što sličnije ispitivanoj skupini. Pojedinačni podaci su bili i ostat će zaštićeni, te nedostupni javnosti, a dostupni su jedino konačni, skupni rezultati istraživanja. Sve ispitanice su usmeno obaviještene o ciljevima istraživanja, te izričito pitane da li žele sudjelovati, a pri tom su mogle odbiti sudjelovanje ili ga dobrovoljno prihvatiti. Kriteriji uključenja u istraživanje bili su: žene oboljele i liječene od raka dojke na području Livna, te zdrave žene (tj. bez raka). Kriteriji isključenja: žene koje nisu članice Udruge žena oboljelih od raka dojke "Bistrica" (klinički uzorak), dob manja od 18 godina, ispitanice s psihijatrijskom dijagnozom, te one s više kroničnih bolesti radi mogućeg utjecaja na kvalitetu života. 


\section{Instrumenti u istraživanju}

U ovom istraživanju analizirani su podaci dobiveni korištenjem upitnika s pitanjima vezanim za demografska i socijalna obilježja, te način stanovanja i upitnika kvalitete života Svjetske zdravstvene organizacije WHOQOL-BREF. Upitnik sa sociodemografskim obilježjima je namjenski sačinjen za ovo istraživanje. Upitnik kvalitete života Svjetske zdravstvene organizacije WHOQOL BREF je kraći oblik upitnika WHOQOL-100. Upitnik u cijelosti sadrži 26 čestica. Kao rezultat upitnika dobiva se profil kvalitete života koji polazi od modela koji objašnjava kvalitetu života kroz 4 područja: tjelesno zdravlje, psihičko zdravlje, socijalni odnosi i okolina (17). Boduje se percepcija kvalitete života u svakoj od 4 domene upitnika posebno (fizičko zdravlje, psihološko stanje, društvena interakcija, te okoliš), pri čemu je skala usmjerena pozitivno, što znači da veći broj bodova predstavlja veću kvalitetu života (određene čestice su negativno kodirane, što je statistički rekodirano prije finalne obrade). Svako se pitanje boduje Likertovom skalom od 1 (najlošije) do 5 (najbolje). Nakon transformacija bodova, koje se vrše u dva koraka, bodovi za pojedinu domenu su unutar skale 0-100. Temeljem ekvidistantne strukture Likertove skale, $\mathrm{u}$ ovom je istraživanju uzeto $\mathrm{u}$ obzir da ispitanice s vrijednošću većom od $60 \%$ skalnog maksimuma (SM) u pojedinoj domeni imaju dobru kvalitetu života u ist istoj domeni, a one s vrijednošću ispod $60 \%$ SM lošu kvalitetu života te specifične domene (18). Podaci su obrađeni metodama deskriptivne i inferencijalne statistike. Raspodjela podataka mjerena je Kolmogorov Smirnovim testom. Kategorijske varijable prikazane su apsolutnim i relativnim frekvencijama, a kontinuirane aritmetičkom sredinom i standardnom devijacijom. U utvrđivanju značajnosti razlike između skupina korišten je Studentov $t$ test za nezavisne uzorke. Razina značajnosti u svim mjerenjima bila je $\mathrm{p}<0.05$. $\mathrm{U}$ statističkoj obradi podataka korišten je programski sustav SPSS 23 (IBM, SAD) i Microsoft Excell 2010.

\section{REZULTATI}

\section{Sociodemografske karakteristike uzorka}

Kod kliničkog uzorka raspon dobi iznosio je 38-76 godina ( $\mathrm{M}_{\mathrm{dob}}=62,78$ god.; $\left.\mathrm{SD}=8,6\right)$, a kod nekliničkog uzorka 40-78 godina $\left(\mathrm{M}_{\mathrm{dob}}=60,12\right.$ god.; $\mathrm{SD}=9,42)$. T-testom se utvrdilo da ne postoji statistički značajna razlika po prosječnoj dobi $(t=1,19$; $\mathrm{df}=63 ; \mathrm{p}=0,239)$. $\mathrm{U}$ ukupnom uzorku $(\mathrm{n}=65)$, njih $29,2 \%$ je bilo zaposleno, 30,7 \% nezaposleno, a 40 $\%$ umirovljeno.

Iz tablice br. 1. je vidljiv odnos žena s rakom dojke $i$ bez raka prema radnom statusu.

Tablica 1. Raspodjela ispitanica prema radnom statusu i bolesti/zdravlju. Rezultati izraženi kao frekvencije.

\begin{tabular}{lcccc}
\hline & & \multicolumn{3}{c}{ Imate li rak dojke? } \\
& Da & Ne & Ukupno \\
\hline \multirow{4}{*}{ Radni status } & Zaposlena & 4 & 15 & 19 \\
& Nezaposlena & 11 & 9 & 20 \\
& Umirovljenica & 17 & 9 & 26 \\
\hline Ukupno & & 32 & 33 & 65 \\
\hline
\end{tabular}

Nije nađena statistički značajna razlika među ispitivanim skupinama vezana za mjesto stanovanja. Najviše ispitanica je bilo u bračnoj zajednici (60 $\%)$, a najmanje je razvedenih (1,5\%). U kliničkom uzorku je bilo manje udanih ispitanica, a samica je sedam puta više, dok su u podjednakom broju razvedene i udovice.

Zadovoljstvo kvalitetom života (opće) ocjenjivalo se na samo jednoj čestici (G1): „Kakvom biste ocijenili kvalitetu svog života?" ocjenama od 1 do 5. Ispitanice iz kliničkog uzorka dale su prosječnu ocjenu 3,8 ( $\mathrm{M}=3,78 ; \mathrm{SD}=0,75)$, dok su ispitanice iz nekliničkog uzorka dale prosječnu ocjenu 3,9 $(\mathrm{M}=3,94 ; \mathrm{SD}=3,7)$. T-testom za nezavisne uzorke pokazalo se da ova razlika nije statistički značajno različita uz stupanj sigurnosti $95 \%(\mathrm{t}=-0,88 ; \mathrm{df}=63$; $\mathrm{p}=0,384)$. Zadovoljstvo zdravljem ocijenjeno je također jednom česticom (G2): „Koliko ste zadovoljni svojim zdravljem?" ocjenama od 1 do 5 . Ispitanice iz kliničkog uzorka dale su prosječnu ocjenu 3,4 $(\mathrm{M}=3,38 ; \mathrm{SD}=0,91)$, dok su ispitanice iz nekliničkog 
uzorka dale prosječnu ocjenu $4(\mathrm{M}=4,00 ; \mathrm{SD}=0,79)$. Utvrđena je statistički značajna razlika uz stupanj sigurnosti $95 \%(t=2,96 ; d f=63 ; p=0,004)$. Detaljan uvid je u tablicama br. 2 i br. 3.

\section{Percepcija kvalitete života na 4 domene}

Upitnikom je mjerena percepcija kvalitete 4 domene života, te su rezultati prikazani za svaku domenu zasebno. Nakon transformacije bodova, bodovi za pojedinu domenu su unutar skale $0-100$, a viši broj predstavlja veće zadovoljstvo. Ispitanice iz kliničkog uzorka najvišom su procjenile kvalitetu svog psihološkog stanja $(\mathrm{M}=64,7 ; \mathrm{SD}=16,5 ; \mathrm{n}=31)$, a najnižom kvalitetu socijalnih interakcija $(\mathrm{M}=60,8$; $\mathrm{SD}=19,7 ; \mathrm{n}=31$ ). Ispitanice nekliničkog uzorka najvišom su procjenile kvalitetu fizičkog zdravlja $(M=73,3 ; S D=16,6 ; n=33)$, a najnižom socijalne interakcije $(M=70,96 ; S D=17,6 ; n=33)$. Ispitanice kliničkog uzorka pokazale su statistički značajno manje zadovoljstvo fizičkim zdravljem od ispitanica nekliničkog uzorka uz stupanj sigurnosti $99 \%(\mathrm{t}=-2,7$; $\mathrm{df}=62 ; \mathrm{p}=0,009 ; \mathrm{M}_{\mathrm{K}}<\mathrm{M}_{\mathrm{NK}}$ ), što je i očekivan rezultat. U ocjeni zadovoljstva psihičkim zdravljem T-testom uz stupanj sigurnosti $95 \%$ nije dokazana statistički značajna razlika između ispitivanih skupina $(\mathrm{t}=$ $\left.-1,7 ; \mathrm{df}=62 ; \mathrm{p}=0,095 ; \mathrm{M}_{\mathrm{K}}=\mathrm{M}_{\mathrm{NK}}\right)$. Ispitanice kliničkog uzorka su pokazale statistički značajno manje zadovoljstvo društvenim interakcijama (socijalna domena) od ispitanica nekliničkog uzorka uz stupanj sigurnosti $95 \%\left(\mathrm{t}=-2,2 ; \mathrm{df}=62 ; \mathrm{p}=0,032 ; \mathrm{M}_{\mathrm{K}}<\mathrm{M}_{\mathrm{NK}}\right)$. T-testom za nezavisne uzorke također je utvrđena statistički značajna razlika u prosječnoj ocjeni zadovoljstva okolišem (okolinskoj domeni) između kliničkog i nekliničkog uzorka. Ispitanice kliničkog uzorka su ocijenile statistički značajno manje zadovoljstvo okolišem od ispitanica nekliničkog uzorka uz stupanj sigurnosti $95 \%(\mathrm{t}=-2,3 ; \mathrm{df}=62 ; \mathrm{p}=0,023$; $\left.\mathrm{M}_{\mathrm{K}}<\mathrm{M}_{\mathrm{NK}}\right)$. Detaljan uvid u tablicama br.2 i br.3.
Tablica 2. Prosječne vrijednosti, raspršenja i standardne pogreške za klinički i neklinički uzorak

\begin{tabular}{|c|c|c|c|c|c|}
\hline & $\begin{array}{l}\text { Imate } \\
\text { li rak } \\
\text { dojke? }\end{array}$ & N & M & SD & SDE \\
\hline Kakvom biste & $\mathrm{Da}$ & 32 & 3,78 &, 751 &, 133 \\
\hline $\begin{array}{l}\text { ocijenili kvalitetu } \\
\text { svog života? }\end{array}$ & $\mathrm{Ne}$ & 33 & 3,94 & ,704 & ,123 \\
\hline Koliko ste & $\mathrm{Da}$ & 32 & 3,38 & ,907 &, 160 \\
\hline $\begin{array}{l}\text { zadovoljni svojim } \\
\text { zdravljem? }\end{array}$ & Ne & 33 & 4,00 & ,791 &, 138 \\
\hline \multirow{2}{*}{ Fizicka domena } & $\mathrm{Da}$ & 31 & 61,29 & 18,9 & 3,41 \\
\hline & $\mathrm{Ne}$ & 33 & 73,27 & 16,5 & 2,88 \\
\hline Psiholoska & $\mathrm{Da}$ & 31 & 64,65 & 16,5 & 2,968 \\
\hline domena & $\mathrm{Ne}$ & 33 & 71,59 & 16,1 & 2,818 \\
\hline \multirow{2}{*}{ Socijalna domena } & $\mathrm{Da}$ & 31 & 60,75 & 19,7 & 3,546 \\
\hline & Ne & 33 & 70,96 & 17,5 & 3,058 \\
\hline \multirow{2}{*}{ Okolinska domena } & $\mathrm{Da}$ & 31 & 62,3 & 16,4 & 2,963 \\
\hline & $\mathrm{Ne}$ & 33 & 71,31 & 14,3 & 2,502 \\
\hline
\end{tabular}

Tablica 3. Rezultati t-testova za nezavisne uzorke između kliničkog i nekliničkog uzorka

\begin{tabular}{|c|c|c|c|c|c|}
\hline & $\mathrm{T}$ & Df & $p$ & $M_{k}-M_{n k}$ & $S D E_{m k}$ \\
\hline Kakvom biste ocijenili &,- 876 & 63 & ,384 & -158 &, 181 \\
\hline kvalitetu svog života? &,- 875 & 62,4 & ,385 &,- 158 & ,181 \\
\hline Koliko ste zadovoljni & $-2,964$ & 63 & ,004 & -,625 & ,211 \\
\hline svojim zdravljem? & $-2,958$ & 61,2 &, 004 & -,625 & ,211 \\
\hline \multirow[t]{2}{*}{ Fizicka domena } & $-2,694$ & 62 &, 009 & $-11,978$ & 4,447 \\
\hline & $-2,682$ & 59,6 &, 009 & $-11,978$ & 4,466 \\
\hline \multirow[t]{2}{*}{ Psihološka domena } & $-1,697$ & 62 &, 095 & $-6,940$ & 4,089 \\
\hline & $-1,696$ & 61,5 &, 095 & $-6,940$ & 4,092 \\
\hline \multirow[t]{2}{*}{ Socijalna domena } & $-2,188$ & 62 & ,032 & $-10,207$ & 4,665 \\
\hline & $-2,180$ & 60 & ,033 & $-10,207$ & 4,683 \\
\hline \multirow[t]{2}{*}{ Okolinska domena } & $-2,333$ & 62 & ,023 & $-9,008$ & 3,861 \\
\hline & $-2,323$ & 59,6 & ,024 & $-9,008$ & 3,878 \\
\hline
\end{tabular}




\section{RASPRAVA}

Rezultatima dobivenim ovim istraživanjem utvrđeno je da se opće zadovoljstvo kvalitetom života kod žena oboljelih od raka dojke ne razlikuje od zadovoljstva kvalitetom života zdravih žena. Zadovoljstvo zdravljem veće je kod zdravih žena u odnosu na oboljele, što je i očekivano. Kvaliteta života u domeni fizičkog zdravlja je statistički značajno niža kod žena oboljelih od raka dojke u odnosu na zdrave žene. Analizom rezultata pokazalo se da od 8 žena koje žive same njih čak 7 je s dijagnozom raka dojke, što može biti indikativno, no obzirom na veličinu uzorka izvođenje zaključka nije moguće.

Rezultati različitih studija pokazuju da je većina ispitanica oboljelih od raka dojke živjela u obitelji. Istraživanje provedeno $\mathrm{u}$ Aleksandriji obuhvatilo je 272 ispitanice koje su se liječile ambulantno ili bolnički. Njihov bračni status je pokazao da je od oboljelih njih 90,8 \% u braku, razvedenih je 4,4\%, udovica $3,3 \%$, a samica $1,5 \%$ (16).

Obzirom na navedeno, zanimljivo bi bilo istražiti vezu između samačkog života i maligniteta općenito na području Livna, te možebitni utjecaj zbunjujućih čimbenika na rezultate istraživanja. U kliničkom uzorku je više visoko obrazovanih žena naspram nekliničkog uzorka. Zadovoljstvo psihičkim stanjem podjednako je kod obje skupine ispitanica, a zadovoljstvo društvenim interakcijama je statistički značajno manje kod ispitanica kliničkog uzorka. Ispitanice iz kliničkog uzorka su manje zadovoljne okolinskom domenom u koju spadaju izvori financija, sloboda i tjelesna sigurnost, dostupnost socijalne i zdravstvene skrbi, dostupnost informacija i usluga, mogućnost rekreacije i prijevoz u odnosu na neklinički uzorak. Ispitanice kliničkog uzorka najzadovoljnije su kvalitetom svog psihološkog stanja, a ispitanice nekliničkog uzorka najviše zadovoljstva iskazuju svojim fizičkim zdravljem. Jedno od mogućih objašnjenja iskazanim zadovoljstvom psihološkim stanjem ispitanica iz kliničkog uzorka je upravo zbog toga što su te ispitanice članice grupe podrške za žene oboljele od raka dojke „Bistrica“, pa im je od početka dostupna psihološka podrška. Drugi mogući razlog je osjećaj pripadnosti socijalnoj grupi koji slijedi iz članstva, a koji također značajno pogoduje psihološkom stanju. Kod oba uzorka najnižom je procijenjena kvaliteta socijalnih interakcija. Razlog ovome možemo tražiti u nerazumijevanju okoline za teškoće $s$ kojima se ispitanice kliničkog uzorka bore, posebice od strane članova obitelji, ali i moguće povlačenje iz društva zbog bolesti. Sukladno našim rezultatima, oboljelim ženama izrazito je važna potpora partnera, obitelji i prijatelja. Sudjelovanje u grupama za potporu ženama oboljelima od raka dojke nosi mnoge koristi jer zbližavanjem s drugim članicama dolazi se do dijeljenja iskustva, osjećaja i informacija (19). Istraživanje je pokazalo da su najveće razlike između oboljelih i zdravih ispitanica u stupnju zadovoljstva prijevoznim sredstvima. Dostupna istraživanja ne navode nezadovoljstvo ispitanica po pitanju prijevoznih sredstava, što upućuje na potrebu za iznalaženjem rješenja koji bi olakšali proces liječenja i rehabilitacije. Zdrave žene su statistički značajno zadovoljnije radnom sposobnošću, sposobnošću obavljanja svakodnevnih aktivnosti i osjećajem fizičke sigurnosti. Žene oboljele od raka dojke teže prihvaćaju svoj tjelesni izgled u odnosu na zdrave žene, što je i očekivano obzirom da se tjelesni izgled, snaga i sposobnost obavljanja svakodnevnih aktivnosti uslijed raka dojke mijenjaju.

Studija koju su proveli Holzner K. i suradnici među ženama oboljelim od raka dojke pokazuje velike probleme vezane uz mentalno zdravlje bolesnica, te dobre rezultate koji se odnose na fizičko zdravlje (20). Zadovoljstvo psihičkim zdravljem kod ispitanica iz kliničkog uzorka ovog istraživanja je netipično $u$ odnosu na rezultate sličnih istraživanja. Potrebno je ispitati utjecaj religioznosti na psihičko zdravlje oboljelih, obzirom na tradicionalan vjerski odgoj karakterističan za ovaj kraj.

Studija provedena u onkološkom centru u Maroku na uzorku od 1463 ispitanice oboljele od raka dojke pokazala je nisko zadovoljstvo općom kvalitetom života u odnosu na studije iz drugih zemalja (21).

Nezadovoljstvo općom kvalitetom života vezano ponajviše uz ograničenost pokreta, te prihvaćanje izmijenjenog tjelesnog izgleda navodi i prospektivna studija provedena u Iranu na 167 ispitanica s dijagnozom raka dojke. Stupanj nezadovoljstva u 
ovim domenama jednak je i 18 mjeseci nakon provedenog tretmana (22). Za buduća istraživanja bilo bi potrebno usporediti ispitanice $\mathrm{u}$ različitim stadijima bolesti jer u našem istraživanju u klinički uzorak uzete su u obzir i žene koje su završile s liječenjem, kao i one kojima je rak tek dijagnosticiran.

\section{ZAKLJUČAK}

Žene oboljele od raka dojke na području Livna procjenjuju opće zadovoljstvo životom bez statistički značajne razlike u odnosu na zdrave žene. Najveće zadovoljstvo iskazuju svojim psihičkim zdravljem što je u suprotnosti sa rezultatima dostupnih kliničkih istraživanja. Utjecaj religioznosti na procjenu kvalitete života kod oboljelih od malignih bolesti na području Livna može biti predmet budućih istraživanja. Najveća razlika između oboljelih i zdravih žena je u zadovoljstvu prijevoznim sredstvima, sposobnosti obavljanja svakodnevnih poslova i prihvaćanju izmijenjenog tjelesnog izgleda. Žene oboljele od raka dojke kao i zdrave žene podjednako su nezadovoljne socijalnim interakcijama.

\section{LITERATURA}

1. Turić M, Kolarić K, Eljuga D. Klinička onkologija. Zagreb: Nakladni zavod Globus; 1996.

2. World Health Organization. Health for all targets. The health policy for Europe. Geneva;1991.

3. World Health Organization. Key facts and Global burden of cancer. Geneva; 2008.

4. Jardines L, Haffty BG, Theriault RL. Early Breast Cancer. In Cancer Managment Pazdur R. ed PRR Huntington N. Y. 1996;21-40.

5. Fajdić J, Đurović D, Gotovac N, Hrgović Z. Bolesti dojke. Zagreb: Nakladni zavod Globus; 1998.

6. Vrdoljak E, Šamija M, Kusić Z, Petković M, Gugić D, Krajina Z. Klinička onkologija. Zagreb: Medicinska naklada; 2013.

7. Zavod za javno zdravstvo Federacije $\mathrm{BiH}$. Zdravstveno statistički godišnjak Federacije Bosne i Hercegovine za 2011. godinu. Sarajevo; 2012.
8. Strnad M, Šogorić S. Rano otkrivanje raka u Hrvatskoj. Acta Med Croatica. 2010;64:461468.

9. Cummins RA. On the trail of the gold standard for life satisfaction. Social Indicators Research. 1995;35:179-200.

10. Cella DF, Tulsky DS. Measuring quality of life today: mathodological aspects. Oncology. 1990;4:29-38.

11. Prlić N, Kadojić D, Kadojić M. Quality of life in post-stroke patients: self-evaluation of physical and mental health during six months. Acta Clin Croat. 2012;51:601-8.

12. Wade TD, Lee C. Prospective predictors of mental health after the development of breast cancer in middle-aged women. Health Psychol. 2005; 24:246-51.

13. Vukota Lj, Mužinić L. Sustavna psihološka i psihosocijalna podrška ženama oboljelima od raka dojke. JAHS. 2015; 1: 97-106.

14. Husić S, Brkljačić Žagrović, M. Izmijenjen tjelesni izgled žene nakon mastektomije zbog karcinoma dojke uzrokuje poremećaj kvalitete života. Medicina Fluminensis. 2010; 46:8085.

15. Ganesh S, Lye MS, Lau FN. Quality of life among Breast Cancer Patients in Malaysia. Asian Pac J Cancer Prev. 2016;17:1677-84.

16. Eminović E, Ovčina A. Kvaliteta života pacijentica oboljelih od karcinoma dojke.(Internet). Pristupljeno 20.03.2017. Dostupno na http://www.hdmsarist.hr/wp-content/uploads/2017/01/Casopis-Rauche-vol-VIII.pdf.

17. Babić I, Babić D, Martinac M. Psihički simptomi i kvaliteta života studenata iz obitelji s iskustvom rata. Zdravstveni glasnik. 2016;2:27-35.

18. Garratt A, Schmidt L, Mackintosh A, Fitzpatrick R. Quality of life measurement:bibliographic study of patient assessed health outcome measures. BMJ 2002;324:1417.

19. Ivanec B. Kvaliteta života i mentalno zdravlje žena oboljelih od raka dojke. Završni rad. Osijek: Odsjek za psihologiju Filozofskog fakulteta u Zagrebu; 2015. 
20. Holzner B, Kemmler M, Moschen R, Schwigkofler H, Dunser M. Quality cancer patients-not enough attention for long-term survivors? Psyhosomatics. 2001;42:117-23

21. El Fakir S, El Rhazi K, Zidouh A, Bennani M, Benider A, Errihani H. i sur. Health-Related Quality of Life among Breast Cancer Patients and Influencing Factors in Morocco.
Asian Pacific Journal Cancer Prevention. 2017;12:5063-5069.

22. Montazeri A, Vahdaninia M, Harirchi I, Ebrahimi M, Khaleghi F, Jarvandi S. Quality of life in patients with breast cancer before and after diagnosis:an eighteen months follow-up study. BMC Cancer 2008;8:330. 


\title{
QUALITY OF LIFE AMONG WOMEN WITH BREAST CANCER LIVING IN LIVNO
}

\author{
Roberta Perković, Andrea Vlašić, Antonija Hrkać, Ivan Vasilj \\ Faculty of Health Studies, University of Mostar, Bijeli Brijeg bb, \\ Mostar 88000, Bosnia and Herzegovina
}

\begin{abstract}
INTRODUCTION: Breast cancer is the most common malignant disease in womenand the risk of cancer increases with age. Today, self-assessment of quality of life in people with malignancy is an objective of many studies, primarily to improve rehabilitation and therapeutic procedures as well as prolonged and better quality survival.

OBJECTIVE: Assess the quality of life among women with breast cancer living in Livno.

SUBJECTS AND METHODS: The cross-sectional study was conducted on the sample of 65 subjects $(\mathrm{n}=65)$. The inclusion criteria were: women suffering and treated from breast cancer living in Livno and healthy women (cancer free). The exclusion criteria were: women who are not members of the Association of women with breast cancer "Bistrica" (clinical sample), subjects under 18 years of age, subjects with psychiatric diagnosis, and subjects with more chronic diseases due to possible impact on the quality of life. The data were collected on the basis of two questionnaires: socio-demographic questionnaire and quality of life questionnaire (WHOQOL-BREF).

RESULTS: In the clinical sample there were more highly educated women and those who lived alone. Subjects from the clinical sample assessed the quality of their psychological state with the highest score and social interactions with the lowest score. There was statistically less satisfaction with physical health in subjects from the clinical sample.

CONCLUSION: There was no significant difference in the overall satisfaction with the quality of life between women with breast cancer and healthy women. The largest difference between women with breast cancer and healthy women wasin the satisfaction with means of transportation, ability to perform everyday tasks, and acceptance of modified physical appearance.

Key words: quality of life, breast cancer, women

Correspondence: Roberta Perković

Fra Mihovil Sučić Hospital Livno

E-mail: rperkovic73@gmail.com
\end{abstract}

